\title{
Successful management of tertiary hyperparathyroidism associated with hypophosphataemic rickets in an adult
}

\author{
Panagiotis Anagnostis ${ }^{1}$, Kyriakos Vamvakidis ${ }^{2}$, Symeon Tournis ${ }^{3}$ \\ 'Unit of Reproductive Endocrinology, First Department of Obstetrics and Gynaecology, Medical School, Aristotle University of \\ Thessaloniki, Thessaloniki, Greece; ²Department of Endocrine Surgery, "Henry Dunant” Hospital, Athens, Greece; \\ ${ }^{3}$ Laboratory for Research of the Musculoskeletal System "Th. Garofalidis”, Medical School, National and Kapodistrian University of \\ Athens, KAT Hospital, Athens, Greece
}

\begin{abstract}
Tertiary hyperparathyroidism (THP) is a rare complication in patients with hypophosphataemic rickets (HR), usually related to long-term management with active vitamin $D$ analogues and oral phosphate salts. If left untreated, THP may aggravate bone and renal disease. We report a case of THP, which developed during the course of HR. Preoperatively, cinacalcet administration along with gradual increase in alphacalcidol dose, led to almost normalization of serum calcium and decrease in parathyroid hormone (PTH) concentrations. The patient underwent an uneventful subtotal parathyroidectomy, resulting in PTH normalization and stabilization of eucalcaemia during 18 months of follow-up. We conclude that, except for optimal dosage of elementary phosphate and alphacalcidol, cinacalcet prior to parathyroidectomy may be an effective option in patients with HR complicated with THP.
\end{abstract}

Keywords: Hypophosphataemia, Rickets, Tertiary Hyperparathyroidism, Cinacalcet, Parathyroidectomy

\section{Introduction}

Chronic hyposphosphataemia is either attributed to decreased phosphate intestinal absorption or increased renal phosphate loss ${ }^{1}$. The most common type of the latter is attributed to increased serum concentrations of fibroblastgrowth factor 23 (FGF-23), an osteocyte/osteoblast-derived phosphatonin, which plays a central role in phosphate and calcium metabolism'. X-linked hypophosphataemia (XLH) is the main representative of FGF-23-associated rickets, usually caused by inactivating mutations of the phosphate-regulating endopeptidase homolog, X-linked (PHEX) gene, leading to inappropriately high FGF-23 levels'. In general, XLH is a rare disease with an estimated incidence of 1 in 20,000 births ${ }^{2}$.

The authors have no conflict of interest.

Corresponding author: Panagiotis Anagnostis MD, MSc, PhD, FRSPH, Unit of Reproductive Endocrinology, First Department of Obstetrics and Gynecology, Medical School, Aristotle University of Thessaloniki, Sarantaporou 10, 54640, Thessaloniki, Greece

E-mail: pan.anagnostis@gmail.com

Edited by: P. Makras

Accepted 24 March 2019
Treatment usually includes daily administration of phosphate salts and active vitamin D analogues (such as alphacalcidol and calcitriol) in various doses ${ }^{1}$. Notably, secondary (SHP) and, more rarely, tertiary hyperparathyroidism (THP) may develop during the course of the disease, further complicating its management ${ }^{3,4}$.

Herein, we report a rare case of hypercalcaemia due to THP, associated with hypophosphataemic rickets, successfully managed with cinacalcet and subtotal parathyroidectomy.

\section{Case presentation}

A 31-year old woman presented to our department due to hypercalcaemia and hypophosphataemia. At presentation, she was being treated with oral alphacalcidol $(0.5 \mu \mathrm{g} /$ day) and phosphate salts ( $5 \mathrm{~g} /$ day, divided in five doses). Extremely high daily doses of alphacalcidol (up to $5 \mu \mathrm{g} /$ day) were reported by the patient during adulthood, probably in an effort to manage secondary hyperparathyroidism. However, based on medical records from the paediatric nephrology department, the patient was treated with up to $1 \mu \mathrm{g}$ of alphacalcidol during childhood. Her paediatric history included severe gait disturbances, clubfoot, bilateral osteotomies of the tibia performed at the age of $7 \mathrm{yrs}$ and 14 
Table 1. Baseline and follow-up of biochemical and hormonal parameters.

\begin{tabular}{|c|c|c|c|c|c|c|}
\hline $\begin{array}{l}\text { Laboratory parameter (units) } \\
\text { (normal range) }\end{array}$ & Baseline' & 1 month & 3 months $^{2}$ & 9 months ${ }^{3}$ & 12 months & 18 months ${ }^{4}$ \\
\hline Serum creatinine $(\mathrm{mg} / \mathrm{dl})(0.5-1.1)$ & 0.56 & 0.54 & 0.51 & 0.7 & 0.82 & 0.52 \\
\hline Serum total calcium (mg/dl) $(8.2-10.2)$ & 11.1 & 10.6 & 10.5 & 9.7 & 9.6 & 9.1 \\
\hline Albumin $(\mathrm{g} / \mathrm{dl})(3-5)$ & 4.3 & 4.1 & 4.1 & 4.2 & 4.4 & \\
\hline Serum phosphate (mg/dl) (2.7-4.5) & 1.8 & 2.1 & 1.5 & 1.8 & 1.5 & 1.5 \\
\hline Serum magnesium $(\mathrm{mg} / \mathrm{dl})(1.7-2.6)$ & & 2.1 & & 1.8 & 2 & \\
\hline Alkaline phosphatase $(\mu \mathrm{IU} / \mathrm{I})(60-120)$ & 95 & 89 & 106 & 77 & 63 & \\
\hline iPTH (pg/ml) (10-65) & 721 & 554 & 358 & 62 & 57 & 51 \\
\hline 25(OH)D (ng/ml) (30-50) & 15 & 19 & & 22.8 & & 24 \\
\hline $1,25(\mathrm{OH})_{2} \mathrm{D}(\mathrm{pg} / \mathrm{ml})(16-42)$ & & 35 & & & & \\
\hline 24-h urinary calcium $(\mathrm{mg})(100-300)$ & 114 & & & & 293 & \\
\hline 24-h urinary phosphate $(\mathrm{mg})(400-1500)$ & & & & & 1690 & \\
\hline \multicolumn{7}{|c|}{$\begin{array}{l}\text { Abbreviations: iPTH: intact parathyroid hormone; } 25(\mathrm{OH}) \mathrm{D} \text { : } 25 \text {-hydroxy-vitamin } \mathrm{D} ; 1,25(\mathrm{OH})_{2} \mathrm{D}: 1 \text {-25-dihydroxy-vitamin } \mathrm{D} \text {. } \\
\text { Notes: } \\
\text { 1. Treatment consisted of alphacalcidol } 0.5 \mu \mathrm{g} / \text { day \& phosphate } 5 \mathrm{~g} / \text { day } \\
\text { 2. Cinacalcet } 30 \mathrm{mg} \text { b.i.d., alphacalcidol } 1.5 \mu \mathrm{g} / \text { day, phosphate } 1 \mathrm{~g} \text { q.i.d., } \\
\text { 3. Immediate post-parathyroidectomy biochemical pattern } \\
\text { 4. Alphacalcidol } 1.5 \mu \mathrm{g} / \text { day, phosphate } 1 \mathrm{~g} \text { b.i.d. }\end{array}$} \\
\hline
\end{tabular}

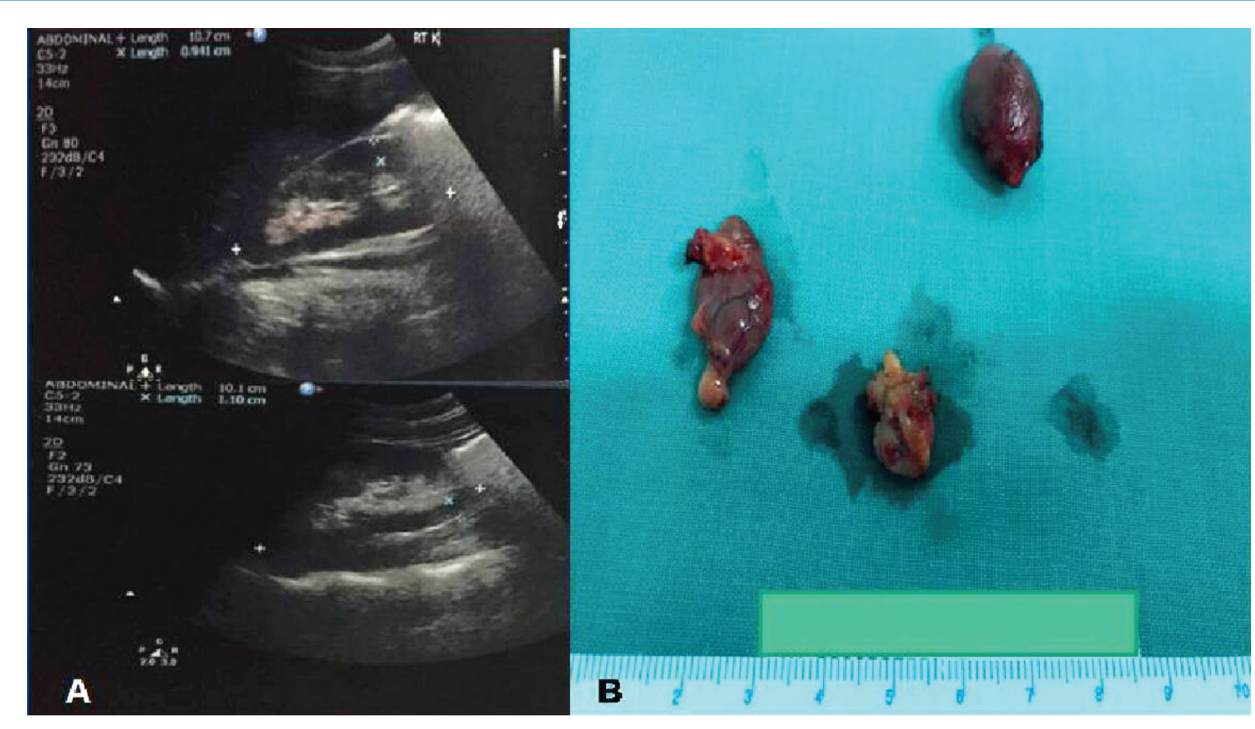

Figure 1. A. Kidney ultrasound indicative of nephrocalcinosis; B. Surgical specimen of three enlarged parathyroid glands.

yrs and tooth deformities during childhood (reconstructions, implants and abscesses), a cluster of abnormalities compatible with the diagnosis of XLH. On physical examination, her body weight and height were $50 \mathrm{~kg}$ and $139 \mathrm{~cm}$, respectively (body mass index: $25.85 \mathrm{~kg} / \mathrm{m}^{2}$ ). Biochemical and hormonal assessment on admission showed mild hypercalcaemia [corrected serum total calcium concentrations: $10.9 \mathrm{mg} / \mathrm{dl}$ (normal range: 8.4-10.4 mg/dl)] and hypophosphataemia [serum phosphate concentrations: $1.8 \mathrm{mg} / \mathrm{dl}$ (normal range 1.9-2.5)], combined with markedly high parathyroid hormone (PTH) [721 pg/ml (normal range 10-65]) and low 25-hydroxy-vitamin D levels [15 ng/ml (suggested concentrations for primary hyperparathyroidism 20-30 $\mathrm{ng} / \mathrm{ml})$ ], respectively. Renal function was normal [estimated glomerular filtration rate (eGFR): $114.9 \mathrm{ml} / \mathrm{min} / 1.73 \mathrm{~m}^{2}$ ], as were the 24-h urinary calcium concentrations [114 mg/24-h (normal range: 50-300)]. 1,25-dihydroxy-vitamin D [1,25 $(\mathrm{OH})_{2} \mathrm{D}$ ] concentrations were normal, given the treatment 
with alphacalcidol (Table 1). Thus, the diagnosis of THP was set. At the age of $14 \mathrm{yrs}$, under no treatment with phosphate salts, the maximum tubular reabsorption of phosphorus factored for glomerular filtration rate (TmP/GFR) was estimated at $0.94 \mathrm{mg} / \mathrm{dl}$ (sCreatinine: $0.6 \mathrm{mg} / \mathrm{dl}, 24 \mathrm{hU}$ Creatinine: $1421 \mathrm{mg}, \mathrm{sP}: 1.7 \mathrm{mg} / \mathrm{dl}, 24 \mathrm{hU}$ Phosphate: 1800 $\mathrm{mg}$, TMP/GFR normal range: $3.73-7.93 \mathrm{mg} / \mathrm{dl}$ ), suggestive of hypophosphataemia due to renal loss of phosphate.

Further investigation included assessment of bone mineral density by dual-energy $X$-ray absorptiometry (DXA) which was normal, whereas renal ultrasonography showed bilateral nephrocalcinosis (Figure 1A). On neck ultrasound, enlargement of the right (inferior and superior) and left superior parathyroid glands was observed. A Tc ${ }^{99 \mathrm{~m}}$ sestamibi scan was indicative of a hyperfunctioning right inferior parathyroid gland.

Initial management included addition of cinacalcet (30 $\mathrm{mg}$ bid), followed by a gradual increase in alphacalcidol dose $(1.5 \mu \mathrm{g} / \mathrm{day})$ leading to almost complete normalization of calcium levels and substantial decrease in PTH levels. Two months later, the patient underwent an uneventful parathyroidectomy, including removal of three enlarged parathyroid glands (Figure 1B). Histological diagnosis was consistent of multiple parathyroid adenomas. Post-operative PTH and calcium concentrations were within normal range, alkaline phosphatase activity progressively decreased and so far remain normal, after a follow-up of 18 months.

\section{Discussion}

Chronic hypophosphataemia results in severe defects in bone matrix mineralization, leading to skeletal deformities from birth, osteomalacia, muscle pain and fractures in later life'. Treatment usually includes daily administration of oral phosphate salts and active vitamin $\mathrm{D}$ analogues in various doses'. Except for impaired growth, other longterm complications of hypophosphataemic rickets, mainly associated with its treatment include nephrocalcinosis and renal failure'. Hyperparathyroidism, either secondary and, more rarely, tertiary, may also develop during the course of the disease, further compromising calcium and phosphate homeostasis ${ }^{3-5}$. The proposed pathogenetic mechanisms include the postprandial reduction in serum calcium concentrations after phosphate ingestion, the decreased $1,25(\mathrm{OH})_{2} \mathrm{D}$ production (attributed both to FGF-23 and phosphate), a direct stimulatory effect of the latter on the parathyroid cells or loss of PHEX function in the parathyroid gland $^{3}$. High $1,25(\mathrm{OH})_{2} \mathrm{D}$ doses may also increase FGF-23 concentrations, creating a vicious cycle ${ }^{6}$.

XLH seems to be the most possible diagnosis of our case, judging by the patient's long history of stable hypophosphataemia, typical of XLH, which by far is the most common cause of hypophosphatemic rickets at this age, the absence of myopathy (generally observed in acquired forms of hypophosphataemia, such as tumor-induced osteomalacia, which is extremely rare at this age) and the low TMP/
GFR. Although we cannot exclude the rare recessive forms [Autosomal Recessive Hypophosphatemic Rickets (ARHR) 1 \& 2], Autosomal Dominant Hypophosphatemic Rickets (ADHR) seems less likely, due to the early and severe phenotype in our case and the stable hyposphosphataemia during the course of the disease as compared with the fluctuating phosphate levels observed in several cases of ADHR ${ }^{1,7}$.

In general, XLH is a rare disease with an estimated incidence of 1 in 20,000 births $^{2}$. It is mostly attributed to inactivating mutations of the PHEX gene, leading to inappropriately high FGF-23 levels'. FGF-23 is the main phosphate regulating hormone, also called phosphatonin, secreted by osteocytes and osteoblasts. The main mechanism of FGF-23 induced hypophosphataemia is the inhibition of the sodium-phosphate symporter $2 \mathrm{a}$ and $2 \mathrm{c}$ at the proximal renal tubule and suppression of $1,25(\mathrm{OH})_{2} \mathrm{D}$ production at the renal tubule by reduced expression of the enzyme 1a-hydroxylase'. Unfortunately, we could neither measure FGF-23 concentrations nor to perform a genetic testing for PHEX mutations.

THP may further aggravate nephrocalcinosis, worsen renal function and complicate bone disease in patients with XLH and, therefore, should be early recognized and successfully treated. Due to the rarity of the disease, the exact incidence of THP in XLH cannot be estimated, but it seems to increase with increasing phosphate doses ${ }^{3}$. Surgical removal of the abnormal parathyroid tissue, during a neck exploration, is the treatment of choice and should be performed by a highvolume surgeon, in order to restore PTH and calcium levels without shifting to the other side, since hypoparathyroidism may also exacerbate renal disease in these patients ${ }^{1,3}$. Diffuse chief-cell hyperplasia is the most possible histological diagnosis ${ }^{1,3}$. Another benefit of successful parathyroidectomy, is that restoration of PTH mitigates the FGF-23 phosphaturic effect ${ }^{6}$. Achievement of adequate vitamin $D$ status prior to surgery should also be taken into account, since it seems to reduce the risk of hungry bone syndrome $e^{1,3-5}$.

There are some reports for a beneficial role cinacalcet prior to parathyroidectomy in XLH cases, as in our case ${ }^{3-5}$. Cinacalcet is a calcimimetic compound which binds to the calcium-sensing receptor in parathyroid cells and enhances its sensitivity to circulating calcium concentrations, thus, decreasing, PTH secretion. It has been approved for cases under hemodialysis and secondary hyperparathyroidism, parathyroid carcinoma or primary hyperparathyroidism (PHP) not subjective to surgery ${ }^{8-11}$. In PHP, normocalcemia is achieved in $70-100 \%$ of asymptomatic patients and in 28$68 \%$ of cases with more severe disease, whereas PTH levels modestly decrease ${ }^{11}$. Almost half of patients with SHP may achieve PTH concentrations $<250 \mathrm{pg} / \mathrm{ml}$ with cinacalcet ${ }^{8}$. The drug is also effective in patients with recurrent or persistent hyperparathyroidism after parathyroidectomy (in $20 \%$ of (cases) $)^{12}$. Cinacalcet has been also shown to normalize calcium and to reduce PTH concentrations in cases with $\mathrm{XLH}^{1,3-5}$. In the latter situation, it can also ameliorate hypophosphataemia, by inhibiting PTH-mediated phosphaturia ${ }^{1,3-5}$. In our case, normalization of calcium levels by cinacalcet, gave as the 
"therapeutic window" to triple the dose of alphacalcidol, thus reducing PTH levels, probably improving mineralization and reducing the risk of severe "hungry bone syndrome". Thus, concomitant use of cinacalcet and alphacalcidol, a form of "block and replace regimen" seems to be an effective therapeutic option in these cases.

Regular assessment of calcium and phosphate homeostasis, even every 3 months, with fine tuning of active vitamin $D$ and phosphate salt treatment, is of outmost importance in order to prevent long term complications. It is possible that new compounds, such as burosumab, a humanized monoclonal antibody against FGF-23, with proven efficacy on mineral homeostasis and quality of life in adults and children with $\mathrm{XLH}^{13,14}$, might also result in prevention of secondary and tertiary hyperparathyroidism.

\section{Conclusions}

THP, although very rare, should be always taken into consideration, as an adverse consequence, when treating patients with hypophosphataemia. Uneventful parathyroidectomy by an experienced surgeon is recommended in most cases in order to avoid aggravation of renal and bone disease. Cinacalcet seems a reasonable option either pre-operatively or in patients who have contraindications to surgery. Nonetheless, optimal dosage of alphacalcidol and phosphate salts, that minimizes treatmentrelated adverse effects, and regular assessment of calcium and phosphate metabolism, is the mainstay of treatment in patients with hypophosphataemic rickets.

\section{References}

1. Kinoshita Y, Fukumoto S. X-Linked Hypophosphatemia and FGF23-Related Hypophosphatemic Diseases: Prospect for New Treatment. Endocr Rev 2018; 39:274-91.

2. Carpenter TO. New perspectives on the biology and treatment of X-linked hypophosphatemic rickets. Pediatr Clin North Am 1997;44:443-66.

3. Tournis S, Georgoulas T, Zafeiris C, Papalexis C, Petraki K, Lyritis GP. Tertiary hyperparathyroidism in a patient with $\mathrm{X}$-linked hypophosphatemic rickets. J
Musculoskelet Neuronal Interact 2011;11:266-9.

4. Yavropoulou MP, Kotsa K, Gotzamani Psarrakou A, et al. Cinacalcet in hyperparathyroidism secondary to $X$-linked hypophosphatemic rickets: case report and brief literature review. Hormones (Athens) 2010;9:274-8.

5. Raeder H, Shaw N, Netelenbos C, Bjerknes R. A case of $\mathrm{X}$-linked hypophosphatemic rickets: complications and the therapeutic use of cinacalcet. Eur $J$ Endocrinol 2008;159 Suppl 1:S101-5.

6. Collins MT, Lindsay JR, Jain A, et al. Fibroblast growth factor-23 is regulated by 1alpha,25-dihydroxyvitamin D. J Bone Miner Res 2005;20:1944-50.

7. Imel EA, Econs MJ. Approach to the hypophosphatemic patient. J Clin Endocrinol Metab 2012;97:696-706.

8. Block GA, Martin KJ, de Francisco AL, et al. Cinacalcet for secondary hyperparathyroidism in patients receiving hemodialysis. N Engl J Med 2004;350:1516-25.

9. Bollerslev J, Marcocci C, Sosa M, Nordenstrom J, Bouillon R, Mosekilde L. Current evidence for recommendation of surgery, medical treatment and vitamin $\mathrm{D}$ repletion in mild primary hyperparathyroidism. Eur $\mathrm{J}$ Endocrinol 2011;165:851-64.

10. Cetani F, Saponaro F, Banti C, et al. Cinacalcet efficacy in patients with moderately severe primary hyperparathyroidism according to the European Medicine Agency prescription labeling. J Endocrinol Invest 2012;35:655-60.

11. Marcocci C, Cetani F. Clinical practice. Primary hyperparathyroidism. N Engl J Med 2011;365:2389-97.

12. Zitt E, Rix M, Urena Torres $P$, et al. Effectiveness of cinacalcet in patients with recurrent/persistent secondary hyperparathyroidism following parathyroidectomy: results of the ECHO study. Nephrol Dial Transplant 2011;26:1956-61.

13. Carpenter TO, Whyte MP, Imel EA, et al. Burosumab Therapy in Children with X-Linked Hypophosphatemia. N Engl J Med 2018;378:1987-98.

14. Insogna KL, Briot K, Imel EA, et al. A Randomized, Double-Blind, Placebo-Controlled, Phase 3 Trial Evaluating the Efficacy of Burosumab, an Anti-FGF23 Antibody, in Adults With X-Linked Hypophosphatemia: Week 24 Primary Analysis. J Bone Miner Res 2018;33:1383-93. 